\title{
Utilização da glutamina, associada ao ácido glutâmico, sobre o desenvolvimento e a atividade enzimática em frangos de corte
}

\author{
[Utilization of glutamine, associated with glutamic acid, on development and enzymatic \\ activity in broiler chickens] \\ M.I. Sakamoto ${ }^{1}$, D.E. Faria ${ }^{1}$, V.S. Nakagi ${ }^{1}$, J.A. Negrão $o^{2}$, R.B. Araújo ${ }^{1}$, \\ K.M.R. Souza ${ }^{1}$, T.C. Previero ${ }^{1}$ \\ ${ }^{1}$ Departamento de Zootecnia - Faculdade de Zootecnia e Engenharia de Alimentos - Universidade de São Paulo \\ Av. Duque de Caxias Norte, 225 \\ 13635-900 - Pirassununga, SP \\ ${ }^{2}$ Departamento de Ciências Básicas - Faculdade de Zootecnia e Engenharia de Alimentos, \\ Universidade de São Paulo - Pirassununga, SP
}

\begin{abstract}
RESUMO
Avaliou-se o efeito da glutamina, associada ao ácido glutâmico, proveniente de um produto comercial, sobre o desenvolvimento e a atividade enzimática em frangos de corte. Foram utilizados 800 pintos de corte, machos, de um a 42 dias de idade, distribuídos em cinco tratamentos, sendo quatro níveis de suplementação do Aminogut ${ }^{\circledR}: 0,5 ; 1,5 ; 3,0$ e 5,0\% + uma dieta-controle, isenta do produto. Observou-se melhor índice de eficiência produtiva para os frangos alimentados com dietas suplementadas com $2,8 \%$ de Aminogut ${ }^{\circledR}$. Independentemente dos tratamentos, verificou-se aumento das atividades da maltase, sacarase e fosfatase alcalina intestinais com o avanço da idade das aves. Para as enzimas pancreáticas, observou-se maior atividade da amilase e lipase aos 14 dias de idade, coincidindo com a maior taxa de crescimento alométrico do pâncreas.
\end{abstract}

Palavras-chave: frango de corte, desempenho, dissacaridases, intestinos, pâncreas

\begin{abstract}
Evaluation of the effect of glutamine associated with glutamic acid in a commercial product, on the growth and enzyme activities in broiler chickens. 800 day-old male broiler chicks were used during the 42 days of trial, and were allotted to five treatments, four levels of Aminogut ${ }^{\circledR}$ supplementation - 0.5, 1.5, 3.0 and $5.0 \%$ + control-diet, free product. The best index of productive efficiency in broiler chickens was observed in those fed diets supplemented with $2.8 \%$ Aminogut ${ }^{\circledR}$. Regardless of the treatment, there was increase in maltase, sucrase and alkaline phosphatase activities as the age of the chickens increased. For pancreatic enzymes, more activity of amylase and lipase can be observed at 14 days of age, coinciding with the highest rate of allometric growth of pancreas.
\end{abstract}

Keywords: broiler chickens, disaccharidases, intestine, pancreas, performance

\section{INTRODUÇÃO}

O avanço genético na avicultura nas últimas décadas tem colaborado no desenvolvimento de frangos de corte com maior taxa de crescimento em menor período de tempo. Dessa forma, a nutrição deve ser balanceada para cada fase de criação, visando atender as necessidades para um crescimento rápido, seguro e saudável (Rostagno et al., 2005a).

Um dos fatores que podem influenciar esse desempenho é o desenvolvimento do trato gastrintestinal (TGI), especialmente durante o período pós-eclosão, quando os segmentos do

Recebido em 18 de julho de 2010

Aceito em 28 de junho de 2011

Email: mizumiss@yahoo.com.br

Projeto financiado pela Fapesp e CNPq 
TGI aumentam em tamanho e peso mais rapidamente que outros órgãos e tecidos (Macari et al., 2002). Entretanto, diferenças com animais adultos são muito prováveis devido, principalmente, às adaptações no sistema digestivo-absortivo. As enzimas digestivas já se encontram ativas no embrião, assim como mecanismos de absorção de nutrientes no intestino. No entanto, a atividade das enzimas digestivas, tanto no pâncreas quanto no conteúdo intestinal, aumenta com a idade do frango (Souza et al., 2005).

A avaliação da mucosa intestinal é um importante aspecto da fisiologia da digestão, pois esta representa uma extensa área de exposição a agentes exógenos que estão presentes no intestino a partir do início da ingestão, digestão e absorção de nutrientes. Em frangos, os processos de desenvolvimento do trato digestório ocorrem, principalmente, nas duas primeiras semanas de idade, o que representa, aproximadamente, 30\% do tempo de vida útil das aves (Maiorka et al., 2000).

A produção enzimática e a estrutura morfológica do sistema digestório das aves altera-se consideravelmente com a frequência do consumo de alimentos (Macari et al., 2002; Souza et al., 2005). Sendo assim, a ingestão de alimentos é considerada um fator limitante para o crescimento de frangos, e nisso o desenvolvimento do TGI tem um importante papel.

Descobertas recentes têm indicado funções adicionais para alguns aminoácidos na manutenção da saúde intestinal, melhorando a digestão e absorção dos nutrientes (Amin et al., 2002; Wang et al., 2008). Dentre estes, encontram-se a glutamina e o ácido glutâmico (Maiorka et al., 2000; Fisher da Silva, 2001; Yi et al., 2005; Li et al., 2007), substâncias com ação trófica sobre a mucosa intestinal. Dessa forma, o objetivo deste experimento foi determinar o melhor nível de suplementação da glutamina, associada ao ácido glutâmico, em dietas de frangos de corte, considerando-se o desenvolvimento e a atividade enzimática de um a 42 dias de idade.

\section{MATERIAL E MÉTODOS}

O experimento foi realizado sob aprovação do Comitê de Ética em Experimentação Animal da Faculdade de Zootecnia e Engenharia de Alimentos da Universidade de São Paulo (CEEA/FZEA-USP). Foram alojados 800 pintos de corte, machos, Cobb-Vantress ${ }^{\circledR}$, peso médio inicial de 47,94 gramas. O delineamento utilizado foi inteiramente ao acaso, com quatro porcentagens de glutamina, associada ao ácido glutâmico (Aminogut $\left.{ }^{\circledR}\right)+$ dieta-controle, isenta de glutamina, totalizando cinco tratamentos com quatro repetições de 40 aves por unidade experimental. As porcentagens avaliadas foram: 0,$5 ; 1,5 ; 3,0$ e 5,0\%. O produto comercial Aminogut ${ }^{\circledR}$ (Ajinomoto Interamericana ${ }^{\circledR}$ ) é uma associação de glutamina (Gln) + ácido glutâmico (Glu) na concentração $>10 \%$, conforme especificações do fabricante.

As dietas foram formuladas à base de milho e farelo de soja, atendendo as exigências nutricionais das aves de acordo com Rostagno et al. (2005b), conforme demonstrado nas Tab. $1 \mathrm{e}$ 2. Na fase de crescimento -22 a 35 dias de idade - e ao abate - 36 a 42 dias -, as aves receberam a mesma dieta basal para todos os tratamentos, de acordo com as exigências nutricionais de cada fase.

As características de desempenho - peso final, ganho de peso, consumo de ração, conversão alimentar e índice de eficiência produtiva foram registradas a cada fase de criação. No sétimo, $14^{\circ}, 21^{\circ}$ e $42^{\circ}$ dias de idade, duas aves por unidade experimental, ou seja, oito aves/tratamento/período, foram retiradas ao acaso e abatidas por deslocamento cervical para colheita dos órgãos do TGI para o acompanhamento do desenvolvimento intestinal de acordo com o peso relativo de cada órgão. Do intestino delgado foram colhidos fragmentos de, aproximadamente, $10 \mathrm{~cm}$ entre o duodeno e o jejuno, abertos longitudinalmente e lavados com solução salina para retirada de todo o conteúdo intestinal, congelados em nitrogênio líquido e armazenados em freezer a $-20^{\circ} \mathrm{C}$ até a realização das análises de atividades enzimáticas. $\mathrm{O}$ mesmo procedimento de armazenamento foi realizado com o pâncreas para as análises enzimáticas. 
Tabela 1. Composição percentual e calculada das dietas pré-iniciais para frangos de corte de um a sete dias de idade, de acordo com a porcentagem de Aminogut ${ }^{\circledR}$

\begin{tabular}{|c|c|c|c|c|c|}
\hline \multirow{2}{*}{$\frac{\text { Ingrediente }}{\text { Aminogut }^{1}}$} & \multirow{2}{*}{ Controle } & \multicolumn{4}{|c|}{$\operatorname{Aminogut~}^{\circledR}(\%)$} \\
\hline & & 0,500 & 1,500 & 3,000 & 5,000 \\
\hline Milho grão & 57,225 & 56,157 & 54,021 & 50,823 & 46,831 \\
\hline Farelo de soja- $45 \%$ & 36,160 & 36,367 & 36,783 & 37,406 & 38,182 \\
\hline Fosfato bicálcico & 1,975 & 1,978 & 1,983 & 1,990 & 1,999 \\
\hline Calcário calcítico & 0,930 & 0,928 & 0,923 & 0,915 & 0,906 \\
\hline Óleo de soja & 1,588 & 1,950 & 2,675 & 3,761 & 5,000 \\
\hline Sal comum & 0,281 & 0,282 & 0,284 & 0,286 & 0,290 \\
\hline Bicarbonato de sódio & 0,357 & 0,356 & 0,355 & 0,352 & 0,335 \\
\hline DL-metionina - 99\% & 0,373 & 0,375 & 0,377 & 0,381 & 0,386 \\
\hline L-lisina $\mathrm{HCl}-99 \%$ & 0,405 & 0,401 & 0,394 & 0,381 & 0,366 \\
\hline L-treonina - 98,5\% & 0,166 & 0,166 & 0,165 & 0,165 & 0,165 \\
\hline Cloreto de colina & 0,030 & 0,030 & 0,030 & 0,030 & 0,030 \\
\hline Suplemento mineral-vitamínico ${ }^{2}$ & 0,500 & 0,500 & 0,500 & 0,500 & 0,500 \\
\hline Antioxidante $^{3}$ & 0,010 & 0,010 & 0,010 & 0,010 & 0,010 \\
\hline \multicolumn{6}{|l|}{ Nível calculado } \\
\hline Energia metabolizável (kcal/kg) & 2.960 & 2.960 & 2.960 & 2.960 & 2.960 \\
\hline Proteína bruta (\%) & 22,10 & 22,10 & 22,10 & 22,10 & 22,10 \\
\hline Cálcio (\%) & 0,98 & 0,98 & 0,98 & 0,98 & 0,98 \\
\hline Fósforo disponível (\%) & 0,48 & 0,48 & 0,48 & 0,48 & 0,48 \\
\hline Metionina+cistina digestível (\%) & 0,96 & 0,96 & 0,96 & 0,96 & 0,96 \\
\hline Metionina digestível (\%) & 0,67 & 0,67 & 0,67 & 0,67 & 0,68 \\
\hline Lisina digestível (\%) & 1,34 & 1,34 & 1,34 & 1,34 & 1,34 \\
\hline Arginina digestível (\%) & 1,34 & 1,35 & 1,35 & 1,36 & 1,37 \\
\hline Treonina digestível (\%) & 0,87 & 0,87 & 0,87 & 0,87 & 0,87 \\
\hline Triptofano digestível (\%) & 0,24 & 0,24 & 0,24 & 0,24 & 0,24 \\
\hline Sódio (\%) & 0,25 & 0,25 & 0,25 & 0,25 & 0,25 \\
\hline Cloro (\%) & 0,20 & 0,20 & 0,20 & 0,20 & 0,20 \\
\hline Potássio (\%) & 0,84 & 0,84 & 0,84 & 0,84 & 0,84 \\
\hline $\operatorname{BED}(\mathrm{mEq} / \mathrm{kg})^{4}$ & 266,38 & 266,60 & 266,90 & 267,30 & 265,84 \\
\hline
\end{tabular}

1- Aminogut ${ }^{\oplus}$ : Ajinomoto Interamericana Ind. e Com. Ltda. : L-ácido glutâmico (>10\%); L-glutamina (>10\%); 60\% $\mathrm{PB} ; 3.646 \mathrm{kcal} / \mathrm{kg} \mathrm{EB}$.

2- Suplemento mineral vitamínico. Níveis de garantia por kg do produto: 2.400 .000 UI vitamina A; 480.000UI vitamina D3; 318,00mg vitamina $\mathrm{K} 3$; 514,00mg vitamina $\mathrm{B} 1 ; 1.382,00 \mathrm{mg}$ vitamina $\mathrm{B} 2 ; 640,00 \mathrm{mg}$ vitamina $\mathrm{B} 6$; $2.880,00 \mathrm{mcg}$ vitamina $B 12 ; 3.000,00 \mathrm{mg}$ vitamina $\mathrm{E} ; 7.120,00 \mathrm{mg}$ niacina; $11.008,00 \mathrm{mg}$ zinco; $3.040,00 \mathrm{mg}$ ácido pantotênico; $220,00 \mathrm{mg}$ iodo; $57,60 \mathrm{mg}$ selênio; $90,00 \mathrm{~g}$ colina; $8.478,00 \mathrm{mg}$ ferro; $2.644,00 \mathrm{mg}$ cobre; $15.148,00 \mathrm{mg}$ manganês; $25.000,00 \mathrm{mg}$ nicarbazina; $1.980,00 \mathrm{mg}$ colistina; 20,00g B.H.T.

3- Butil-Hidróxi-Tolueno (BHT).

4- Balanço eletrolítico da dieta (Mongin,1981): $\mathrm{BED}=\left[\begin{array}{lll}(\% & \mathrm{Na} * 10.000 / 22,990)+(\% & \mathrm{K} * 10.000 / 39,102)\end{array}\right)-(\%$ $\left.\mathrm{Cl}^{*} 10.000 / 35,453\right)$.

Para a extração dos zimogênios e determinação da atividade enzimática, o pâncreas foi descongelado, pesado, homogeneizado em um homogeneizador tipo Turrax, utilizando-se uma solução fosfato Tris- $\mathrm{HCl} 50 \mathrm{mM}, \mathrm{pH} 8,0$, na proporção de 1:4 (peso:volume), centrifugado a $14.000 x g$ por 30 minutos sob refrigeração a $4^{\circ} \mathrm{C}$, filtrado, armazenado a $-70^{\circ} \mathrm{C}$ e posteriormente utilizado para a determinação da atividade enzimática da amilase, lipase e tripsina. A ativação do tripsinogênio do pâncreas foi realizada por meio da pré-incubação com a Enterokinase (E-0632 SIGMA $\left.^{\circledR}\right)$, por 30 minutos, na presença de tampão Tris- $\mathrm{HCl} 0,5 \mathrm{M}$; pH 8,0, contendo $\mathrm{CaCl}_{2} \cdot 2 \mathrm{H}_{2} \mathrm{O}$ 0,05M. Após a ativação, a atividade da tripsina foi determinada 
de acordo com Kakade et al. (1974), em que a reação foi obtida pela hidrólise de p-nitroaniline benzoyl-DL-arginine-(BAPNA-SIGMA ${ }^{\circledR}$ ) ao meio de incubação. Após três minutos de incubação a $37^{\circ} \mathrm{C}$, a reação foi interrompida pela adição de $0,20 \mathrm{~mL}$ de ácido acético $30 \%$. Foram centrifugados, e a p-nitroanilida liberada foi determinada em espectrofotômetro (HITACHI U-2000 a 410nm). A atividade foi expressa em nmol p-nitroaniline liberada por minuto por miligrama de proteína.

Tabela 2. Composição percentual e calculada das dietas iniciais para frangos de corte de 8 a 21 dias de idade, de acordo com a porcentagem de Aminogut ${ }^{\circledR}$

\begin{tabular}{|c|c|c|c|c|c|}
\hline \multirow{2}{*}{$\frac{\text { Ingrediente }}{\text { Aminogut }^{1}}$} & \multirow{2}{*}{$\begin{array}{c}\text { Controle } \\
-\end{array}$} & \multicolumn{4}{|c|}{ Aminogut $^{\circledR}(\%)$} \\
\hline & & 0,500 & 1,500 & 3,000 & 5,000 \\
\hline Milho grão & 61,062 & 59,307 & 57,172 & 53,967 & 50,483 \\
\hline Farelo de soja- $45 \%$ & 33,379 & 34,181 & 34,600 & 35,228 & 35,365 \\
\hline Fosfato bicálcico & 1,880 & 1,879 & 1,884 & 1,891 & 1,905 \\
\hline Calcário calcítico & 0,762 & 0,757 & 0,752 & 0,745 & 0,738 \\
\hline Óleo de soja & 1,500 & 1,983 & 2,708 & 3,796 & 5,100 \\
\hline Sal comum & 0,295 & 0,296 & 0,298 & 0,301 & 0,304 \\
\hline Bicarbonato de sódio & 0,206 & 0,204 & 0,202 & 0,200 & 0,200 \\
\hline DL-metionina - $99 \%$ & 0,179 & 0,188 & 0,188 & 0,189 & 0,194 \\
\hline L-lisina $\mathrm{HCl}-99 \%$ & 0,233 & 0,210 & 0,201 & 0,189 & 0,207 \\
\hline L-treonina - 98,5\% & 0,064 & 0,055 & 0,055 & 0,054 & 0,064 \\
\hline Cloreto de colina & 0,030 & 0,030 & 0,030 & 0,030 & 0,030 \\
\hline Suplemento mineral-vitamínico ${ }^{2}$ & 0,400 & 0,400 & 0,400 & 0,400 & 0,400 \\
\hline Antioxidante $^{3}$ & 0,010 & 0,010 & 0,010 & 0,010 & 0,010 \\
\hline \multicolumn{6}{|l|}{ Nível calculado } \\
\hline Energia metabolizável (kcal/kg) & 3.000 & 3.000 & 3.000 & 3.000 & 3.000 \\
\hline Proteína bruta (\%) & 21,00 & 21,00 & 21,00 & 21,00 & 21,00 \\
\hline Cálcio (\%) & 0,88 & 0,88 & 0,88 & 0,88 & 0,88 \\
\hline Fósforo disponível (\%) & 0,46 & 0,46 & 0,46 & 0,46 & 0,46 \\
\hline Metionina+cistina digestível (\%) & 0,75 & 0,76 & 0,76 & 0,76 & 0,75 \\
\hline Metionina digestível (\%) & 0,47 & 0,48 & 0,48 & 0,48 & 0,48 \\
\hline Lisina digestível (\%) & 1,15 & 1,15 & 1,15 & 1,15 & 1,15 \\
\hline Arginina digestível (\%) & 1,27 & 1,29 & 1,30 & 1,30 & 1,29 \\
\hline Treonina digestível (\%) & 0,75 & 0,75 & 0,75 & 0,75 & 0,75 \\
\hline Triptofano digestível (\%) & 0,23 & 0,23 & 0,23 & 0,23 & 0,23 \\
\hline Sódio (\%) & 0,21 & 0,21 & 0,21 & 0,21 & 0,21 \\
\hline Cloro $(\%)$ & 0,21 & 0,21 & 0,21 & 0,21 & 0,21 \\
\hline Potássio (\%) & 0,79 & 0,80 & 0,81 & 0,81 & 0,80 \\
\hline $\mathrm{BED}(\mathrm{mEq} / \mathrm{kg})^{4}$ & 237,77 & 240,20 & 240,53 & 241,02 & 239,00 \\
\hline
\end{tabular}

1- Aminogut ${ }^{\circledR}:$ Ajinomoto Interamericana Ind. e Com. Ltda. : L-ácido glutâmico (>10\%); L-glutamina (>10\%); 60\% $\mathrm{PB} ; 3.646 \mathrm{kcal} / \mathrm{kg} \mathrm{EB}$.

2- Suplemento mineral vitamínico. Níveis de garantia por kg do produto: 2.000.000UI/kg Vitamina A; 480.000 UI Vitamina D3; 318.00mg Vitamina K3; 514.50mg Vitamina B1; $1.382 .40 \mathrm{mg}$ Vitamina B2; 632.55mg Vitamina B6; $3.000 .00 \mathrm{mcg}$ Vitamina B12; 3.000.00mg Vitamina E; 7.425.00mg Niacina; $15.000 .00 \mathrm{mg}$ Zinco; 3.036.00mg Ácido Pantotênico; 300.00mg Iodo; 86.40mg Selênio; 105.00g Colina; $11.017 .00 \mathrm{mg}$ Ferro; 3.603.00mg Cobre; 20.652.00mg Manganês; 37.50g antioxidante; 20.00g Coccidiostático; 9.375g Promotor de crescimento; $1.000 .00 \mathrm{~g}$ Veículo Q.S.P.

3- Butil-Hidróxi-Tolueno (BHT).

4- Balanço eletrolítico da dieta (Mongin,1981): $\left.\mathrm{BED}=\left[\begin{array}{lll}(\% & \mathrm{Na} * 10.000 / 22,990)+(\% & \mathrm{K} * 10.000 / 39,102\end{array}\right)\right]-(\%$ $\mathrm{Cl} * 10.000 / 35,453)$. 
A atividade da lipase foi determinada empregando-se o método colorimétrico, com a utilização de kit comercial (Quibasa Química Básica - Bioclin-K025). A lipase hidrolisa os triacilglicerois liberando ácidos graxos e monoacilglicerois e, durante a reação, o substrato em meio tamponado e estabilizado adquire uma forma emulsificada - micelas - formando interfaces - lipídeos-água - necessárias à ação da lipase, que, em presença do ácido ditionitrobenzoico, forma um cromógeno amarelo, cuja intensidade de cor é proporcional à atividade da enzima e apresenta absorção máxima em $414 \mathrm{~nm}$. A atividade da amilase foi determinada pelo método iodométrico, a $630 \mathrm{~nm}$, segundo metodologia de Caraway (1959), que se baseia no princípio de que a amilase promove a hidrólise do amido com a liberação de moléculas de carboidratos e dextrina. Pela adição de iodo, o amido não hidrolisado torna-se azul. A atividade da amilase é inversamente proporcional à intensidade do azul e calculada pela comparação com um controle de substrato. Uma unidade amilolítica foi considerada como sendo a quantidade de enzima necessária para hidrolisar 10mg de amido em 30 minutos, nas condições da reação.

O extrato enzimático das amostras de intestino delgado foi obtido a partir da raspagem com lâmina de vidro na mucosa do segmento colhido. A mucosa foi pesada e homogeneizada em homogeneizador tipo Potter, diluída em água destilada gelada na proporção de 1:4 (peso:volume). $\mathrm{O}$ extrato obtido foi centrifugado a $4^{\circ} \mathrm{C}$ por 15 minutos a $14.000 x g$. Para a determinação da atividade das dissacaridases intestinais - maltase e sacarase -, foi utilizado espectrofotômetro a 492nm, segundo Dahlqvist (1964). Alíquotas do homogeneizado foram incubadas com substratos apropriados - sacarose ou maltose -, e a glicose liberada durante a reação foi determinada pelo método de glicoseoxidase, utilizando-se kits comerciais (Laborlab). Foi determinada uma reta padrão de glicose com concentrações conhecidas, a qual foi utilizada para a determinação da concentração da atividade das enzimas, conforme programa Multiskan MS Primary EIA (Versão-1.8-0). A fosfatase alcalina foi determinada por espectrofotometria (590nm), de acordo com a metodologia de Roy (1970) modificada. A enzima presente na amostra hidrolisa o substrato de timolftaleína monofosfato, liberando timolftaleína e fosfato inorgânico, no tempo predeterminado de 10 minutos. A atividade enzimática é proporcional à quantidade de timolftaleína formada, que é medida colorimetricamente. Com a adição do reagente de cor $-\mathrm{Na}_{2} \mathrm{CO}_{3} 150 \mathrm{mmol} / \mathrm{L}$ e $\mathrm{NaOH}$ $100 \mathrm{mmol} / \mathrm{L}$-, a reação é inativada e a timolftaleína torna-se azul. A unidade de atividade específica das enzimas foi definida como sendo a quantidade de enzima que hidrolisa $1 \mu \mathrm{moL}$ de substrato por miligrama de proteína por minuto. A proteína total do extrato do pâncreas e da mucosa intestinal foi quantificada por meio de kits para determinação de proteína total (Protal - Laborlab). As amostras foram mensuradas em espectrofotômetro a $570 \mathrm{~nm}$.

Os dados obtidos foram submetidos às análises de variância, e as médias comparadas pelo teste Tukey, em até $6 \%$ de probabilidade, de acordo com a característica avaliada, considerando-se coeficientes de variação até $30 \%$ aceitáveis para as características enzimáticas. $\mathrm{O}$ melhor nível de suplementação da glutamina, associada ao ácido glutâmico, foi determinado por regressão polinomial, utilizando-se o programa estatístico SAS (2002).

\section{RESULTADOS E DISCUSSÃO}

Os resultados médios das características de desempenho dos frangos de corte, nas diferentes fases, encontram-se na Tab. 3, e o desdobramento das regressões em função dos níveis de Aminogut ${ }^{\circledR}$ nas Fig. 1, 2 e 3. Para o período de um a sete dias de idade, observou-se efeito linear crescente $(\mathrm{P} \leq 0,05)$ para as características peso vivo e ganho de peso, conforme demonstrado na Fig. 1. A conversão alimentar apresentou efeito linear decrescente $(\mathrm{P} \leq 0,05)$ à medida que a porcentagem de Aminogut ${ }^{\circledR}$ foi elevada. Comportamento semelhante foi observado para o período de um a 21 dias de idade (Fig. 2). Para o período total de criação, observou-se efeito quadrático do Aminogut ${ }^{\circledR}(P \leq 0,05)$ sobre o índice de eficiência produtiva (IEP), cujo resultado mais alto foi obtido com 2,8\% de suplementação (Fig. 3).

Avellaneda et al. (2008), ao avaliarem a inclusão de Aminogut ${ }^{\circledR}-0,5 ; 1,0$ e $1,5 \%$ - em dietas para 
frangos de corte, observaram aumento no ganho de peso e diminuição no consumo de ração com a inclusão das porcentagens avaliadas, consequentemente, melhora na conversão alimentar dos frangos. Concluíram que a suplementação de $1,5 \%$ foi satisfatória para um bom desempenho dos frangos de um a 25 dias de idade.

Em relação à atividade enzimática específica da mucosa intestinal, os valores médios encontramse na Tab. 4. Observou-se aumento na concentração de maltase, sacarase e de fosfatase alcalina à medida que as aves cresceram, corroborando com dados da literatura (Nir,1998; Noy e Sklan,1998). Pesquisas têm demonstrado que esses efeitos podem ser atribuídos à suplementação de algum tipo de aditivo fornecido nas dietas, tais como probiótico ou prebiótico (Iji et al., 2001; Pinheiro, 2005). Da mesma forma, Lima et al. (2003) e Pinchasov et al. (1990) sugeriram que a atividade das enzimas digestivas no intestino delgado corresponde à quantidade de conteúdo intestinal e varia diariamente de acordo com a alimentação.

Observou-se efeito linear crescente para a atividade da maltase $(\mathrm{P}=0,052)$ aos 14 dias e para a sacarase $(\mathrm{P}=0,009)$ aos 42 dias de idade, em aves alimentadas com níveis crescentes de Aminogut $^{\circledR}$ (Fig. 4).

Quanto à concentração da atividade enzimática específica do pâncreas, não houve efeito significativo $(\mathrm{P}>0,06)$ dos tratamentos sobre nenhuma das características avaliadas. No entanto, de acordo com a média total, observouse maior concentração da amilase e lípase aos 14 dias, e da tripsina aos sete dias de idade (Fig. 5).

Tabela 3. Valores médios das características de desempenho de frangos de corte alimentados com dietas contendo diferentes porcentagens de Aminogut ${ }^{\circledR}$

\begin{tabular}{|c|c|c|c|c|c|c|c|c|}
\hline \multirow[b]{2}{*}{ Característica } & \multirow{2}{*}{$\begin{array}{l}\text { Controle } \\
\text { (isento) }\end{array}$} & \multicolumn{4}{|c|}{ Aminogut $^{\circledR}(\%)$} & \multirow[b]{2}{*}{$\mathrm{CV}(\%)$} & \multirow[b]{2}{*}{ Valor P } & \multirow[b]{2}{*}{ Regr. } \\
\hline & & 0,5 & 1,5 & 3,0 & 5,0 & & & \\
\hline \multicolumn{9}{|c|}{1 a 7 dias de idade } \\
\hline Peso final (g) & $193,3 b$ & $193,3 b$ & $207,2 \mathrm{ab}$ & $209,6 a$ & $208,52 a$ & 2,25 & 0,0031 & $\mathrm{~L}$ \\
\hline Ganho de peso (g) & $146,0 \mathrm{~b}$ & $145,6 b$ & $158,7 \mathrm{ab}$ & $162,1 \mathrm{a}$ & $159,97 \mathrm{a}$ & 2,95 & 0,0001 & $\mathrm{~L}$ \\
\hline $\begin{array}{l}\text { Consumo de ração } \\
(\mathrm{g})\end{array}$ & 158,3 & 163,4 & 162,9 & 161,1 & 157,8 & 1,75 & ns & ns \\
\hline $\begin{array}{l}\text { Conversão } \\
\text { alimentar (g/g) }\end{array}$ & $1,084 a b$ & $1,123 \mathrm{a}$ & $1,027 \mathrm{ab}$ & $0,994 b$ & $0,987 b$ & 2,11 & 0,0001 & $\mathrm{~L}$ \\
\hline \multicolumn{9}{|c|}{1 a 21 dias de idade } \\
\hline Peso final (g) & $1004,1 b$ & $1028,8 b$ & $1039,6 \mathrm{ab}$ & $1051,6 \mathrm{a}$ & $1028,9 \mathrm{ab}$ & 2,35 & 0,0062 & $\mathrm{~L}$ \\
\hline Ganho de peso (g) & $956,7 \mathrm{~b}$ & $980,9 b$ & $991,1 \mathrm{ab}$ & $1004,1 \mathrm{a}$ & $980,6 a b$ & 2,45 & 0,0056 & $\mathrm{~L}$ \\
\hline $\begin{array}{l}\text { Consumo de ração } \\
\text { (g) }\end{array}$ & 1302,2 & 1313,1 & 1314,1 & 1311,1 & 1292,7 & 1,88 & ns & ns \\
\hline $\begin{array}{l}\text { Conversão } \\
\text { alimentar (g/g) }\end{array}$ & $1,362 \mathrm{a}$ & $1,338 \mathrm{ab}$ & $1,326 a b$ & $1,306 b$ & $1,319 b$ & 1,52 & 0,0017 & $\mathrm{~L}$ \\
\hline \multicolumn{9}{|c|}{1 a 42 dias de idade } \\
\hline Peso final (g) & 2969,1 & 2969,2 & 2937,3 & 2965,5 & 2930,8 & 2,99 & $\mathrm{~ns}$ & ns \\
\hline Ganho de peso (g) & 2921,7 & 2921,3 & 2888,8 & 2917,9 & 2882,3 & 2,02 & ns & ns \\
\hline $\begin{array}{l}\text { Consumo de ração } \\
\text { (g) }\end{array}$ & 4838,6 & 4837,2 & 4913,2 & 4784,4 & 4786,3 & 3,04 & ns & ns \\
\hline $\begin{array}{l}\text { Conversão } \\
\text { alimentar (g/g) }\end{array}$ & 1,656 & 1,655 & 1,701 & 1,640 & 1,661 & 2,98 & ns & ns \\
\hline IEP & $401,1 \mathrm{a}$ & $400,2 \mathrm{ab}$ & $367,8 \mathrm{~b}$ & $400,9 \mathrm{ab}$ & $398,42 \mathrm{ab}$ & 4,17 & 0,0240 & $\mathrm{Q}$ \\
\hline
\end{tabular}

Valores seguidos por letras diferentes na mesma linha diferem entre si pelo teste Tukey $(\mathrm{P} \leq 0,05)$; ns $=$ não significativo $(\mathrm{P}>0.05)$; IEP= índice de eficiência produtiva; Regr= efeito da regressão (L=Linear, $\mathrm{Q}=\mathrm{Quadrático})$. 

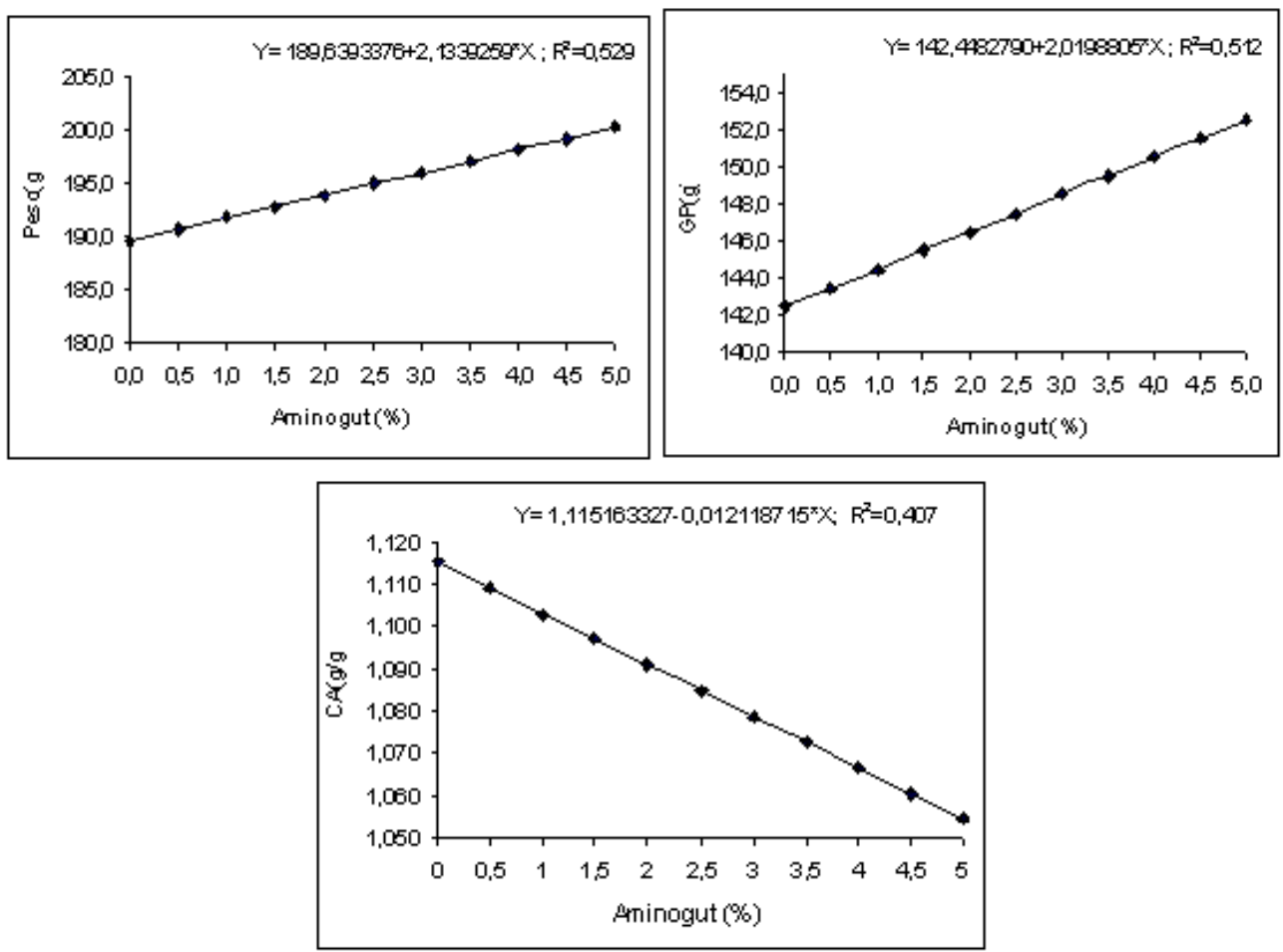

Figura 1. Equações de regressão das características de desempenho de frangos de corte, aos sete dias de idade, alimentados com dietas suplementadas com Aminogut ${ }^{\circledR}$.
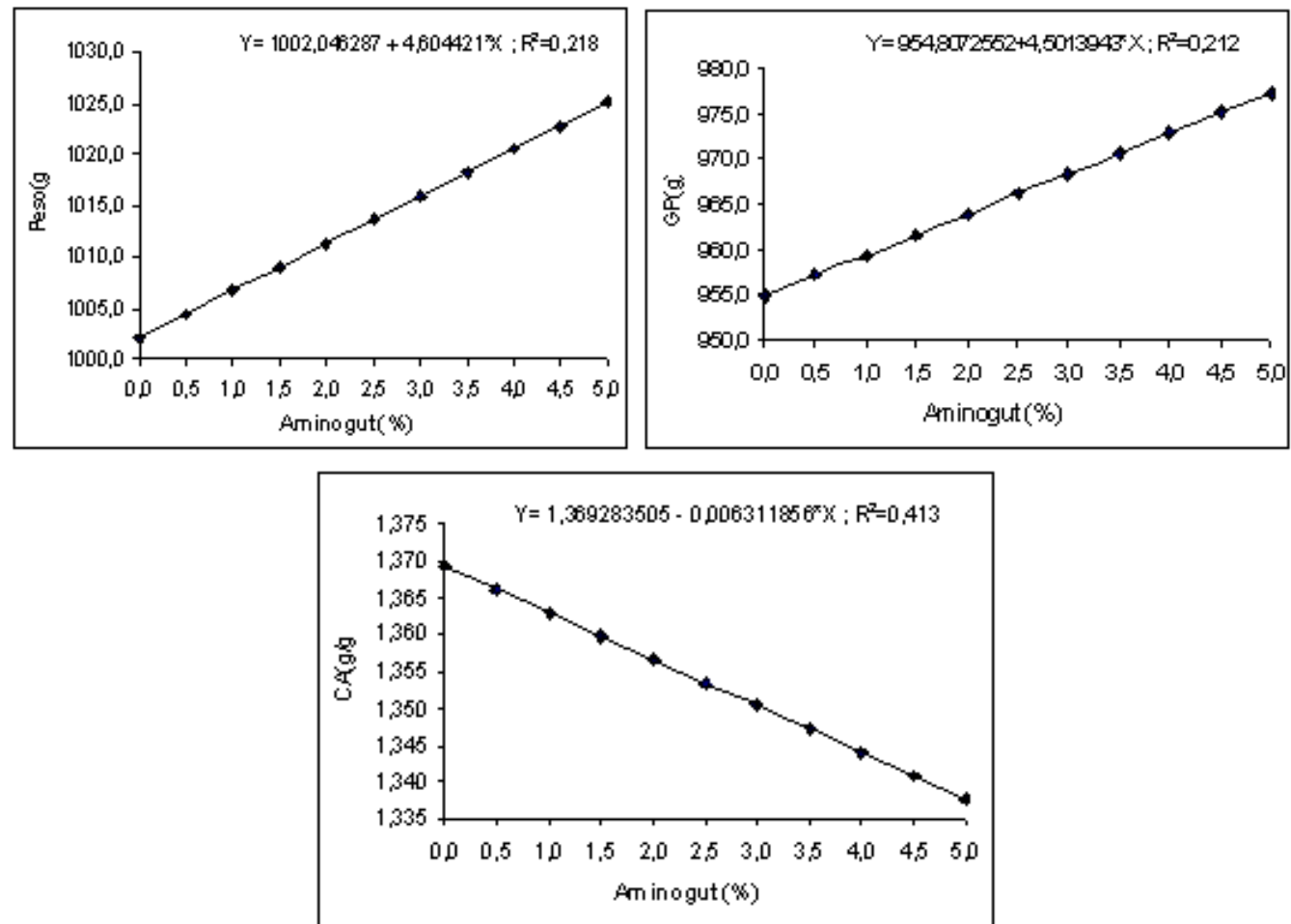

Figura 2. Equações de regressão das características de desempenho de frangos de corte, aos 21 dias de idade, alimentados com dietas suplementadas com Aminogut ${ }^{\circledR}$. 


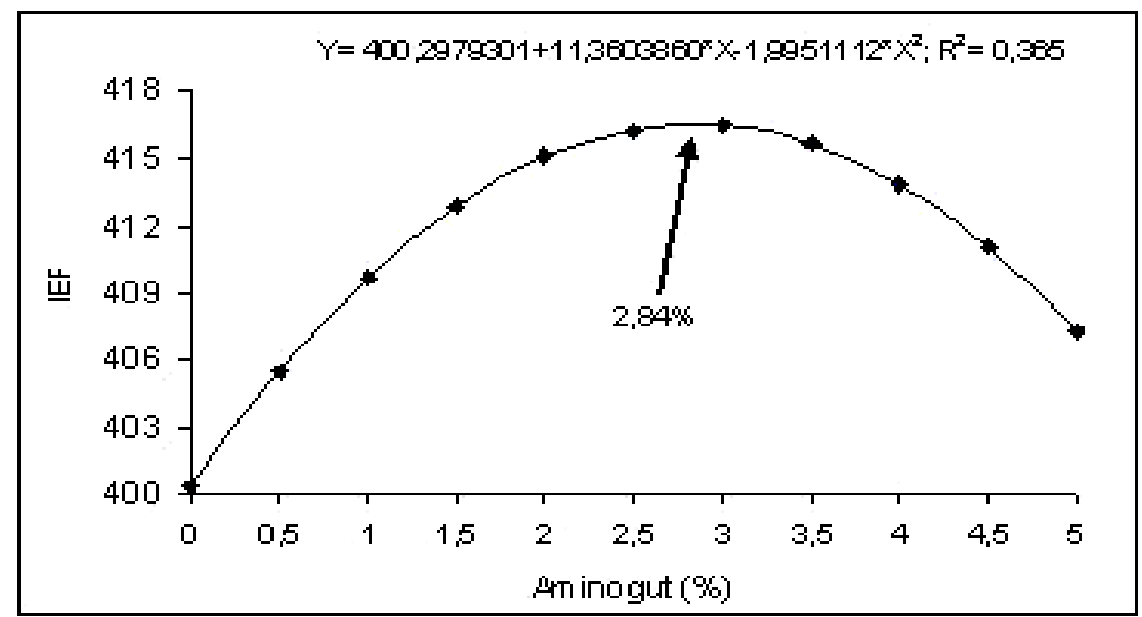

Figura 3. Equação de regressão do índice de eficiência produtiva (IEF) de frangos de corte, aos 42 dias de idade, alimentados com dietas suplementadas com Aminogut ${ }^{\circledR}$.

Tabela 4. Média da atividade enzimática específica ( $\mu \mathrm{mol} / \mathrm{mg}$ proteína/min) para a maltase, sacarase e fosfatase alcalina da mucosa intestinal de frangos de corte alimentados com dietas contendo diferentes porcentagens de Aminogut ${ }^{\circledR}$

\begin{tabular}{|c|c|c|c|c|c|c|c|c|c|}
\hline \multirow[b]{2}{*}{ Característica } & \multirow{2}{*}{$\begin{array}{c}\text { Controle } \\
\text { (isento) }\end{array}$} & \multicolumn{5}{|c|}{$\operatorname{Aminogut}^{\circledR}(\%)$} & \multirow[b]{2}{*}{$\mathrm{CV}$} & \multirow[b]{2}{*}{ Valor P } & \multirow[b]{2}{*}{ Regr. } \\
\hline & & 0,5 & 1,5 & 3,0 & 5,0 & Média & & & \\
\hline \multicolumn{10}{|c|}{7 dias de idade } \\
\hline Maltase & 1,95 & 1,41 & 1,36 & 1,69 & 2,12 & $1,67 \mathrm{~A}$ & 26,37 & $\mathrm{~ns}$ & ns \\
\hline Sacarase & 9,86 & 7,52 & 6,50 & 4,45 & 5,69 & $6,89 \mathrm{~B}$ & 28,97 & ns & ns \\
\hline Fosfatase alcalina & 201,70 & 179,00 & 228,70 & 215,90 & 219,90 & $210,0 \mathrm{~B}$ & 23,70 & $\mathrm{~ns}$ & ns \\
\hline \multicolumn{10}{|c|}{14 dias de idade } \\
\hline Maltase & $0,72 b$ & $1,17 \mathrm{ab}$ & $1,21 \mathrm{ab}$ & $1,26 a b$ & $1,33 \mathrm{a}$ & $1,17 \mathrm{AB}$ & 14,70 & 0,052 & $\mathrm{~L}$ \\
\hline Sacarase & 6,11 & 6,20 & 9,06 & 8,51 & 8,40 & $7,65 \mathrm{~B}$ & 23,89 & ns & ns \\
\hline Fosfatase alcalina & 403,60 & 643,30 & 571,30 & 423,90 & 586,80 & $525,9 \mathrm{~A}$ & 25,31 & ns & ns \\
\hline \multicolumn{10}{|c|}{21 dias de idade } \\
\hline Maltase & 1,83 & 1,74 & 1,50 & 0,98 & 1,41 & $1,48 \mathrm{~B}$ & 14,99 & $\mathrm{~ns}$ & $\mathrm{~ns}$ \\
\hline Sacarase & 10,79 & 8,22 & 8,62 & 7,95 & 10,05 & $9,13 \mathrm{~B}$ & 23,83 & ns & ns \\
\hline Fosfatase alcalina & 622,60 & 472,20 & 473,20 & 458,80 & 608,80 & $527,7 \mathrm{~A}$ & 26,05 & $\mathrm{~ns}$ & $\mathrm{~ns}$ \\
\hline \multicolumn{10}{|c|}{42 dias de idade } \\
\hline Maltase & 1,24 & 1,21 & 1,67 & 2,05 & 1,71 & $1,58 \mathrm{~A}$ & 22,37 & ns & ns \\
\hline Sacarase & $7,97 \mathrm{~b}$ & $12,66 \mathrm{ab}$ & $13,63 \mathrm{ab}$ & $14,73 \mathrm{ab}$ & $16,70 \mathrm{a}$ & $13,14 \mathrm{~A}$ & 19,55 & 0,009 & $\mathrm{~L}$ \\
\hline Fosfatase alcalina & 420,20 & 544,40 & 608,80 & 647,50 & 530,80 & $550,8 \mathrm{~A}$ & 20,30 & $\mathrm{~ns}$ & ns \\
\hline
\end{tabular}

Valores seguidos por letras diferentes minúsculas na linha e maiúsculas na coluna, por característica nas diferentes idades, diferem entre si pelo teste Tukey $(\mathrm{P} \leq 0,06)$; ns= não significativo $(\mathrm{P}>0,06)$; Regr= efeito da regressão (L=Linear) 

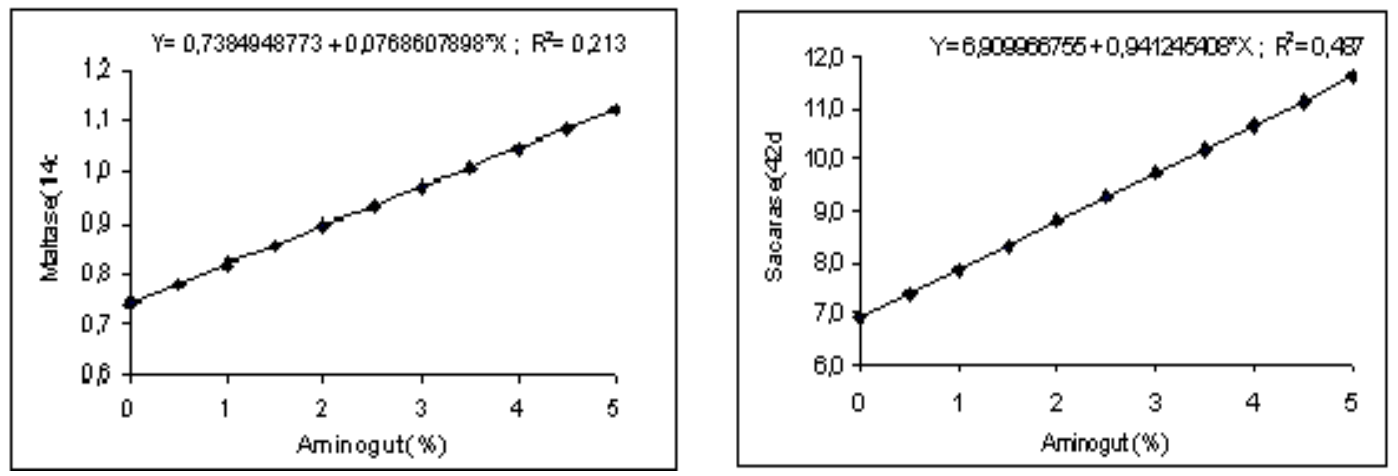

Figura 4. Equações de regressão da atividade enzimática específica ( $\mu \mathrm{mol} / \mathrm{mg}$ proteína/min) para maltase (14 dias de idade) e sacarase (42 dias de idade) de frangos de corte, alimentados com dietas suplementadas com Aminogut ${ }^{\circledR}$.

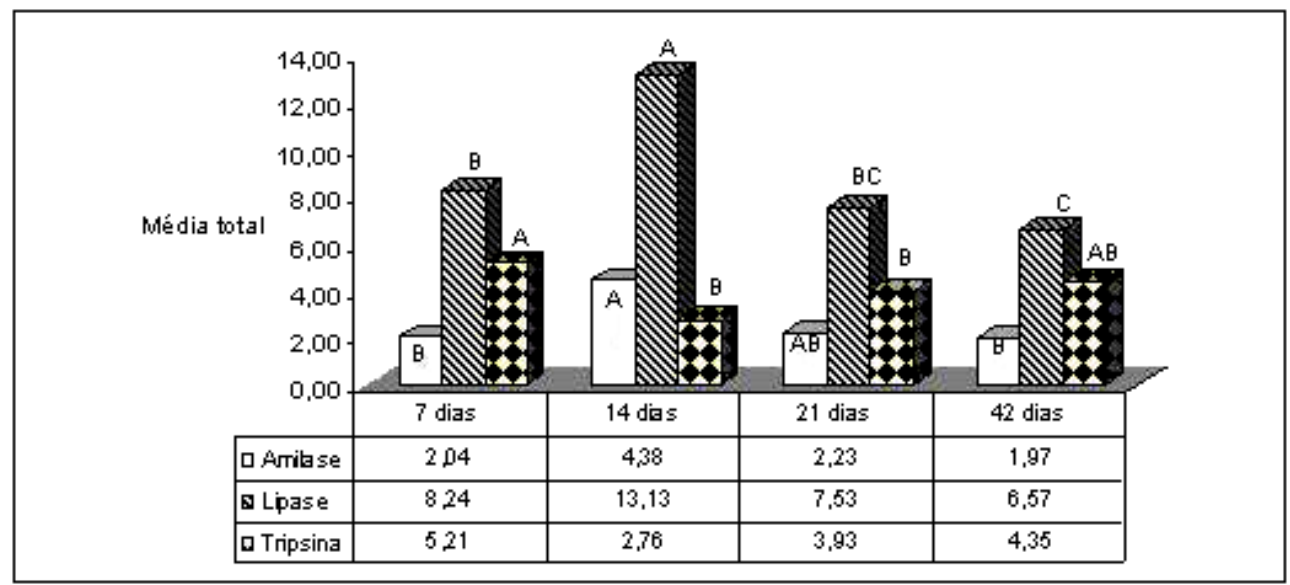

Figura 5. Comportamento médio da atividade enzimática específica (U/mg de proteína/min) do pâncreas de frangos de corte, alimentados com dietas suplementadas com Aminogut ${ }^{\circledR}$, de acordo com a idade.

O comportamento observado para a atividade da amilase é semelhante aos observados por Monteiro et al. (2006) e Lima et al. (2003), que constataram maior atividade dessa enzima aos 14 dias de idade, coincidindo com a maior taxa de crescimento do pâncreas e diminuição da atividade com o avançar da idade das aves, confirmando os estudos de Rodrigues (2001), que avaliou níveis de ácido glutâmico associado à vitamina $\mathrm{K}$ em aves dos sete aos 21 dias de idade e observou maior atividade de $\alpha$-amilase pancreática nas aves aos 14 dias de idade, isto é, o desenvolvimento alométrico do pâncreas atinge o pico máximo ao redor da segunda semana de idade e tende a diminuir, posteriormente.

Sakomura et al. (2004) observaram aumento linear da amilase de acordo com a idade das aves, assim como o crescimento alométrico do pâncreas, que acompanha a curva de crescimento do frango. Porém, a maior taxa de crescimento foi observada nas primeiras semanas de idade, fase em que ocorre a maturação fisiológica dos órgãos digestivos. Nesse mesmo estudo, os autores verificaram aumento linear da atividade da lipase e da tripsina com o avançar da idade das aves, concluindo que o maior incremento na produção das enzimas digestivas coincidiu com o máximo crescimento alométrico do pâncreas.

Atualmente, pouco se conhece sobre as interrelações da cadeia de aminoácidos sobre a integridade da mucosa intestinal, sendo, portanto, importante tópico para futuras pesquisas. No entanto, com base em alguns estudos recentes com humanos e animais, observou-se que glutamina, glutamato e arginina podem ser utilizados na manutenção da saúde e na prevenção de doenças intestinais (Wang et al., 2009). 


\section{CONCLUSÃO}

A suplementação de glutamina, associada ao ácido glutâmico, foi satisfatória para o desempenho dos frangos de corte, sendo recomendada a inclusão de $2,8 \%$ à dieta das aves.

\section{AGRADECIMENTOS}

À Fundação de Amparo a Pesquisa do Estado de São Paulo (FAPESP) e ao Conselho Nacional de Desenvolvimento Científico e Tecnológico $(\mathrm{CNPq})$, pela concessão ao apoio financeiro.

\section{REFERÊNCIAS BIBLIOGRÁFICAS}

AMIN, H.J.; ZAMORA, S.A.; McMILLAN, D.D. et al. Arginine supplementation prevents neocrotizing enterocolitis in the premature infant. $J$. Pediatr., v.140, p.425-431, 2002.

AVELLANEDA, Y.; HERNÁNDEZ, J.; ARIZA, C. et al. Efecto de la suplementación del glutamina y L-glutamato (Aminogut ${ }^{\circledR}$ ) sobre el crecimiento temprano de pollos de engorde. Rev. Med. Vet. Zootec., v.55, p.77-90, 2008.

CARAWAY, W.T. A stable starch substrate for the determinations of amylase in serum and other body fluids. Am. J. Clin. Pathol., v.32, p.97-99, 1959.

DAHLQVIST, D. Method for assay of intestinal disaccharidases. Anal. Biochem., v.7, p.18-25, 1964.

FISHER DA SILVA, A.V. Efeitos da restrição alimentar precoce e da glutamina no desempenho e na mucosa intestinal em frangos. 2001. 77f. Tese (Doutorado em Produção Animal) - Faculdade de Ciências Agrárias e Veterinárias, Universidade Estadual Paulista, Jaboticabal, SP.

IJI, P.A.; SAKI, A.; TIVEY, D.R. Body and intestinal growth of broiler chicks on a commercial starter diet, 2. Development and characteristics of intestinal enzymes. Br. Poult. Sci., v.42, p.514-522, 2001.

KAKADE, M.L.; RACKIS, J.J.; McGHEE, J.G. Determination of trypsin inhibitor activity of soy products: A collaborative analysis of na improved procedure. Cereal Chem., v.51, p.376-382, 1974.

LI, P.; YIN, Y.L.; LI, D.F. et al. Amino acids and immune function. Br. J. Nutr., v.98, p.237-252, 2007.
LIMA, A.C.F.; PIZAURO Jr, J.M.; MACARI, M. et al. Efeito do uso de probiótico sobre o desempenho e atividade de enzimas digestivas de frangos de corte. Rev. Bras. Zootec., v.32, p.200207, 2003.

MACARI, M.; FURLAN, R.L.; GONZALES, E. Fisiologia aviária aplicada a frangos de corte. 2.ed. Jaboticabal: FUNEP/UNESP, 2002. 375p.

MAIORKA, A.; FISCHER DA SILVA, A.V.; SANTIN, E. et al. Influência da suplementação de glutamina sobre o desempenho e o desenvolvimento de vilos e criptas do intestino delgado de frangos. Arq. Bras. Med. Vet. Zootec., v.52, p. 487-490, 2000.

MONTEIRO, M.P.; MORAES, G.H.K.; FANCHIOTTI, F.E. et al. Alfa-amilase em frangos de corte: efeitos do balanço eletrolítico e do nível proteico da dieta. Rev. Bras. Zootec., v.35, supl., p.1070-1076, 2006.

NIR, I. Mecanismos de digestão e absorção de nutrientes durante a primeira semana. In: CONFERÊNCIA APINCO DE CIÊNCIA E TECNOLOGIA AVÍCOLAS - SIMPÓSIO INTERNACIONAL SOBRE MANEJO DE PINTOS DE CORTE, 1, 1998, Campinas. Anais... Campinas: FACTA, 1998. p.81-91.

NOY, Y.; SKLAN, D. Metabolic responses to early nutrition. J. Appl. Poult. Res., v.7, p.437-451, 1998.

PINCHASOV, Y.; NIR, I.; NITSAN, Z. Metabolic and anatomical adaptations of heavy-bodied chicks to intermitent feeding. 2. Pancreatic digestive enzymes. Br. Poult. Sci., v.31, p.769-777, 1990.

PINHEIRO, D.F. Probióticos, prebióticos e simbióticos sobre o sistema digestório de frangos de corte. 2005. 109f. Tese (Doutorado em Nutrição e Produção Animal) - Faculdade de Medicina Veterinária e Zootecnia, Universidade Estadual Paulista, Botucatu, SP.

RODRIGUES, A.C.P. Níveis de ácido L-glutâmico $e$ de vitamina $K$ no desempenho e deformidades ósseas e perfil de enzimas digestivas de pintos de corte alimentados com dietas purificadas. 2001. 130f. Tese (Doutorado em Zootecnia) Universidade Federal de Viçosa, Viçosa, MG.

ROSTAGNO, H.S.; HASHIMOTO, F.A.M.; ALBINO, L.F.T. et al. Desafios na nutrição de frangos de corte. In: FÓRUM INTERNACIONAL DE AVICULTURA, 1, 2005. Foz do Iguaçu. Anais... Foz do Iguaçu: AveWorld, 2005a. p.309318. 
ROSTAGNO, H.S.; ALBINO, L.F.T.; DONZELE, J.L. et al. Tabelas brasileiras para aves e suínos: composição de alimentos e exigências nutricionais. 2. ed. Viçosa: UFV, 2005b. 186p.

ROY, A.V. Rapid method for determining alkaline phosphatase activity in serum with thymolphthalein monophosphate. Clin. Chem., v.16, p. 431-436, 1970.

SAS Institute 2002. SAS ${ }^{\circledR}$ Statistical Analysis System. User's Guide: Statistics. Version 9.1. 4ed., Cary. NC. 2002.

SAKOMURA, N.K.; DEL BIANCHI, M.; PIZAURO Jr., J.M. et al. Efeito da idade dos frangos de corte sobre a atividade enzimática e digestibilidade dos nutrientes do farelo de soja e da soja integral. Rev. Bras. Zootec., v.33, p.924-935, 2004.

SOUZA, A.V.C.; ROSTAGNO, H.S.; DIONIZIO, M.A. et al. Fundamentos técnicos para utilização de dietas pré-iniciais para frangos de corte. In: FÓRUM INTERNACIONAL DE AVICULTURA, 1, 2005, Foz do Iguaçu. Anais... Foz do Iguaçu: AveWorld, 2005. p.207-228.
WANG, J.J.; CHEN, L.X.; LI, P. et al. Gene expression is altered in piglet small intestine by weaning and dietary glutamine supplementation. $J$. Nutr., v.138, p.1025-1032, 2008.

WANG, W.W.; QIAO, S.Y.; LI, D.F. Amino acids and gut function. Amino Acids, v.37, p.105-110, 2009.

YI, F.G.; ALLEE, G.L.; KNIGHT, C.D. et al. Impact of glutamine and oasis hatchling supplement on growth performance, small intestinal morphology, and immune response of broilers vaccinated and challenged with Eimeria maxima. Poult. Sci., v.84, p.283-293, 2005. 